\title{
PROJECT RISK IDENTIFICATION OF A NEW PRODUCT IN ENTERPRISE IN SLOVAKIA \\ Matej Masár ${ }^{1}$, Mária Hudáková
}

\begin{abstract}
Enterprises want to focus on successfully managed projects. Projects must be focused on fulfilling project expectations and setting project objectives. It is necessary to ensure the early identification of project risks. If managers understand and know project risks, they can mitigate them. They can use mitigation to prevent projects from failing, or financial loses in the company. The main aim of this paper is the identification of project risks of a new product in a particular company in the Slovak Republic using the method of brainstorming. Risks can positively but mainly negatively affect the implementation of the proposed project. The proposed project was created based on the methods of analysis, forecasting, comparison, synthesis and provided information from a specific enterprise. The identified risks are grouped into the specified project implementation categories, in order to better identify the identified risks as well as to implement other project risk management steps. The results of the study show that early identification of project risks should be a responsibility for project team members, for top managers and the corporate culture of each enterprise.
\end{abstract}

JEL Classification Numbers: G32, L21, M21, O22; DOI: http://dx.doi.org/10.12955/cbup.v6.1180

Keywords: risk, project, risk identification, enterprise

\section{Introduction}

Project risk management is a main part of project management. Projects are very comprehensive, with higher costs and more team members take part in these projects nowadays. Projects must reflect new trends, projects management standards, trends, processes, and techniques. Project management is very turbulent part of management and more and more important nowadays. The risk management process is significant for each project. It is necessary to exploit the benefits and minimalize the impact of negative risks.

Project management is a well-known term. PMBOK (2004) defines project management as the application of knowledge, skills, tools, and techniques to project activities to meet project requirements. This definition describes the term project management very unclearly. Project management is integrated into a lot of enterprises activities and processes nowadays. Enterprises use project management when they want to create new products, realize R\&D activities, plan for the future, plan and realize some changes, etc.. It is possible to say, that every process, action or activity, enterprises take can run as a project in general.

The main goal of this paper is to identify the project risks of a new product in a particular company in the Slovak Republic, which can positively but also negatively affect the successful implementation of the proposed project. The risk identification is created in accordance to the phases of the proposed project of the new product in the phases of development, production, and sales. The proposed project consists of a product description, a project timeline, project budget and project financial metrics.

\section{Literature Review}

ISO 31000:2009 provides generic guidelines and principles for risk management. This principle can be used by any enterprise, group, association or individual. It is possible to apply this principle to any type of risk. The risk management process consists of six steps (establishing the context, risk identification, risk analysis, risk evaluation, monitoring and review, communication and consultation) (ISO 31000:2009, 2009).

Olechowski (2017) defines the following main key success factors for project risk management: supports realistic, open, and honest recognition of project risks even; realistic talking and consulting every risk; leading an open discussion about risk; realistic and high-quality data; participation of all team members and comities.

The purpose of the risk identification step is generating a comprehensive list of risks based on those events that might create, enhance, prevent, degrade, accelerate, or delay the achievement of objectives. The main characteristics objectives, which are important in this step, must be described and the team must have identified positive risks (opportunities) and negative risks (threats) (ISO 31000:2009, 2009).

\footnotetext{
${ }^{1}$ Faculty of Security Engineering, University of Zilina, matej.masar@fbi.uniza.sk

${ }^{2}$ Faculty of Security Engineering, University of Zilina, maria.hudakova@ fbi.uniza.sk
} 
Positive and negative risks must be mainly identified and those risks and risk circumstances be described. The risk identification phase can be divided into 3 parts - methods for a risk identification (short description of methods, which will be used); risk identification (use methods in the particular case) and summary of the risks (description of risks, risk consequence, and risk cause) (PMI, 2017).

The benefit of risk identification is using the risk management process. It is possible to consider, that risk identification is the main gate to identify opportunities and threats. It can provide a new and comprehensive view of a project, and the decision about project characteristics.

PMBOK (2004) defines a project as a temporary endeavor undertaken to create a unique product or service. Temporary means that every project has a definite beginning and definite end. Unique means that the product or service is different in some distinguishing way from all other products or services. Project risk management is a part of project management, which deals with risks, which can occur in a project. The project risk management process helps project sponsors and project teams make informed decisions regarding alternative approaches to achieving their objectives and the relative risk involved in each, in order to increase the likelihood of success in meeting or exceeding the most important objectives (e.g. time) sometimes at the expense of other objectives (e.g. cost). Risk management encourages the project team to take appropriate measures to minimize adverse impacts to the project scope, cost, and schedule (and quality, as a result), maximize the opportunities to improve the project's objectives with lower cost, shorter schedules, enhanced scope and higher quality, and minimize management by crisis (OSPMI, 2007).

New trends in project management are annually described by the organization. For the year 2018, the following main trends in project management are established:

- meet business agile - it is possible to define as create and use new ways of doing business,

- devOps will be considered a part of Agile - Create and exploit new IT technology,

- the internet of things and artificial intelligence combine into a powerhouse of actionable information,

- millennial project managers will make their debut and bring new knowledge and skills,

- integration of risk identification to project risk management process - It is considered a main part of project risk management, which may bring new benefits (Burger, 2017), (PMI, 2017), (KPMG, 2017), (Stanleigh, 2017).

\section{Data and methodology}

Data, which was used to create this paper, was obtained from analysis home and abroad literature, scientist's papers, and internet resources. The most important data, which was used to solve the main goal, were provided by managers in a BPS product company in Slovakia. The proposed project in the company was created by using methods of analysis, benchmarking, forecasting and synthesis.

The method of brainstorming was used to identify risks. This method was used because it is one of the best methods for risk identification. Brainstorming is often used in the organization, which prepares the project. Stark (2011) defines the following brainstorming steps, which were used:

- Prepare the group - in this step were chosen the team members, who identified the project risks. 6 team members were chosen. The part of this step is usually called a meeting with the team.

- Define the problem - This step consists of conditions and variables which determine the project.

- Generate Ideas - After the presentation of the project context, every member of the team suggests risks which may affect the project from external, internal or project environment. Every idea was recorded on a flipchart.

- Reduce Ideas - After the break (duration max. 10 minutes), it was necessary to reduce the suggested risks ideas, which were written more times.

- Conclusion - The conclusion is a very important step in risk identification. It was necessary to choose the five main risks. The next support sub-step consisted of defining risk triggers and adding risk descriptions.

The identified risks were graphically illustrated and sorted by the tool "Risk work breakdown structure". It was possible to sort each risk and explain their consequences by this tool. 


\section{Results and Discussion}

\section{The project proposal for a new product in a particular enterprise}

The project development, production, and sales of the new product was created through analysis of scientific articles, benchmarking, forecasts and information, all of which were provided by managers in the enterprise.

This project is very new for this company. Enterprise BPS produce a variety electrotechnical products, but they do not manufacture this category of product. The company wants to develop, manufacture and sell a complete product in this project. It is necessary to describe the consequences, which are important for the identification of project risks. Those consequences are projected specification, product description, product strategy, project timeline, project financial metrics and project budget. Main project consequences are illustrated in Figure 1. The project context consists of the internal environment and project environment. Each project obtains its main parts, which affect the project.

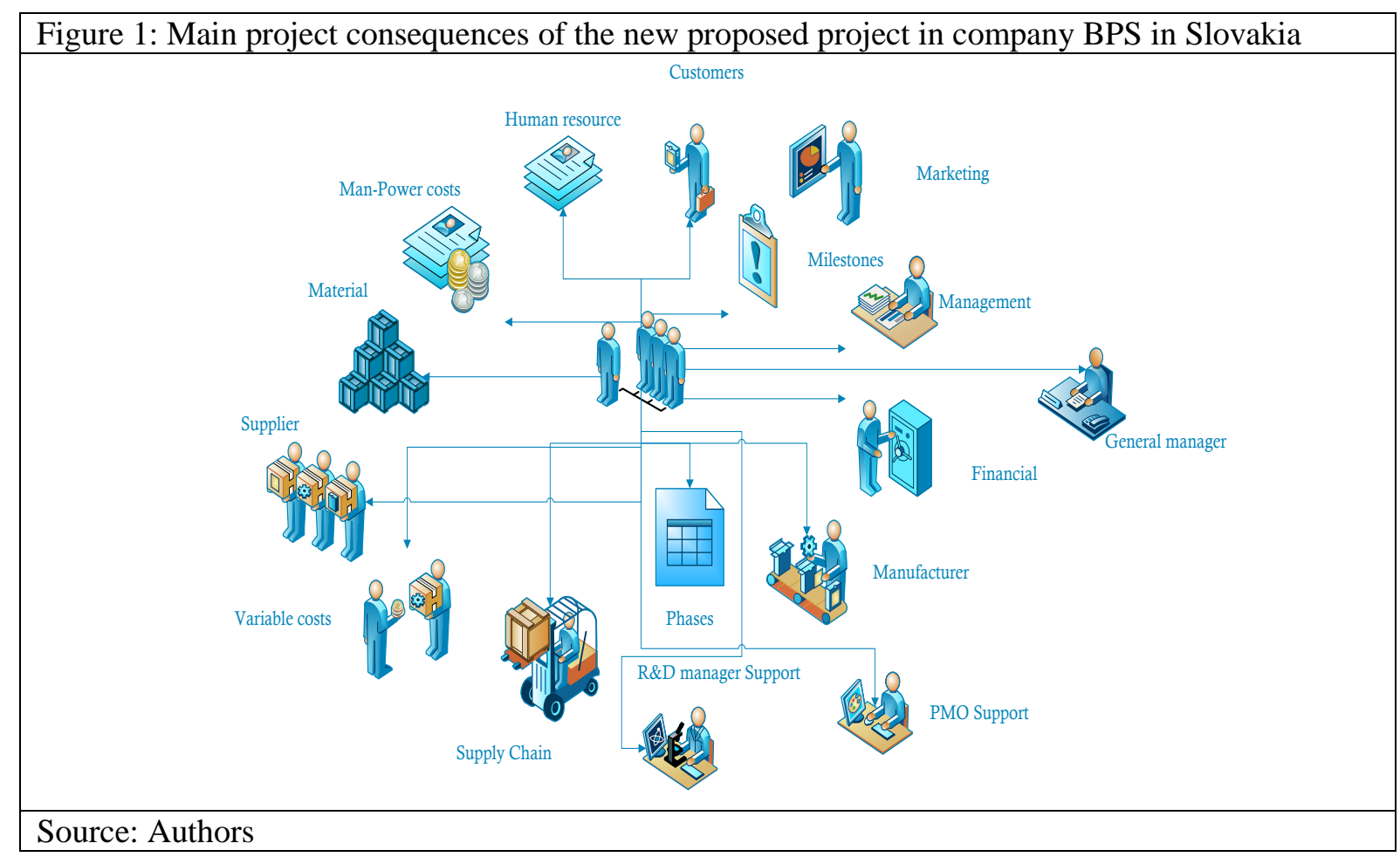

The team established the project (internal) and external contexts. The risks may appear from the external and project environments. The risk management context was established and described in this phase, too.

The main conditions for the acceptance of project are that the project must be in accordance with the visions and strategy of the enterprise. The new project brings the organization lot of benefits. The main benefit was creating a new portfolio of products and the diversification of the product portfolio. Other benefits were better competitiveness, penetration in new markets and gaining new customers. If the project was successful it would be possible to create a new product family.

The main project idea was to create multi-feature welding machine, which was designed to customer expectations. The product was able to weld with three welded methods MMA, MIG-MAG, and TIG. The main objective of the project was entering the market in Central Europe with a new product welding machine. The design, development and manufacture of new welding machine which was directed by modern features which customers wanted.

The net present value (NPV) is possible to define as some difference between present value of future cash flow of investment and the number of each investment. If the number is zero, it means that the project repays investments. Positive NPV value means a better return, while a negative vale a worse return. The NPV was $\$ 45 \mathrm{k}$ in this project. This means that the company can accept this project through the NPV financial metric because they get more money than they will invest into the project. 
Discounted Payback Period is a financial metrics which determines the profitability of a project. It gives the number in year, months, and days when the project will be in profit. It means that all expenses will be at this point paid. DPP was 2.65 in our project. This means, that the projected increase to the break point was 2 years and 7 months.

Internal Rate of Return (IRR) is a financial metrics, which is related to the financial metric NPV. The Internal Rate of Return is the interest rate at which the net present value of cash flow is equal to zero. The IRR was $45.5 \%$ on this project.

It is necessary to describe the risks which most appeared in similar projects in the enterprise.

Insufficient market analysis and research and insufficient analysis of market trends in the industry. Rationale and sufficient market research and analysis are used to help make better decisions when the project is in first phase feasibility study. Market research and analysis can discover, reduce, or validate some risks and for example improve financial metrics. But if we do qualitative and quantitative analysis, it takes a lot of time and costs lot of money. Overtime, the timeline and over cost budget are factors, which influence the quality of marketing research and analysis. The risks which can appear are: the product is without actual trends, the product don't except customer expectations, the demand for the product is very low, etc.

Market dynamics. Market dynamics are defined as pricing signals that are created as a result of changing supply and demand levels in a given market. Market dynamics describes the dynamic, or changing price signals that result from the continual changes in both supply and demand of any particular product or group of products. Market dynamics is a fundamental concept in supply, demand, and pricing economic models (Investopedia, 2013). The risks which can appear in project are: the product do not reflect actual trends, the product does not reflect the customer expectations and the product does not have enough technical progress for the customer.

Changes in the internal environment of the organization. Those changes caused revocation of many projects, changed key customers and left experienced staffs.

Customers have vague requirements for the products. This risk consists of fewer product characteristics and product descriptions by customers. This risk brings an increased budget, and overtime more resources are needed for the project implementation.

\section{Identification of project risks of a new product in an enterprise}

The rroject risks of the new product were identified by using the brainstorming method and the "Risk Work Breakdown Structure" tool. The risks were the sorted into the specified project implementation categories (Figure 2). The identified risks may affect positive or negative this specific project. Project risk identification was conducted through the following steps:

Step 1: Prepare the group - We choose main members, which participated in risk identification. Those staff had knowledge and skills about the risks which can appear in the project and the team can use their skills from similar projects. The group consisted of:

- Project management office manager (PMO) - The PMO was chosen, because he can bring to the team more ideas and the team can use his knowledge and skills from his experience on other projects. The PMO is also as a main support resource for the project team.

- Manager of Engineering Electrical Design, R\&D (MR\&D) - MR\&D has a lot of knowledge about risks, which can appear in the product lifecycle during the first phase.

- Engineer of Electrical Design - A core team member, who co-operated on the project.

- Project manager - A core team member who actively co-operating on the project and lead meeting, including a description of each risk.

Step 2: Define the problem - The problem was defined during the presentation, which was consist of establishing the project context. The presentation consisted of the main project objectives

Step 3: Generate Ideas - We started generating ideas after the presentation during the meeting. We generated 46 risks, which can affect a project.

Step 4: Reduce Ideas - We started to reduce the risks and selected 22 main risks.

Step 5: Conclusion - We sorted the risks and established risk consequences and events in this step. 


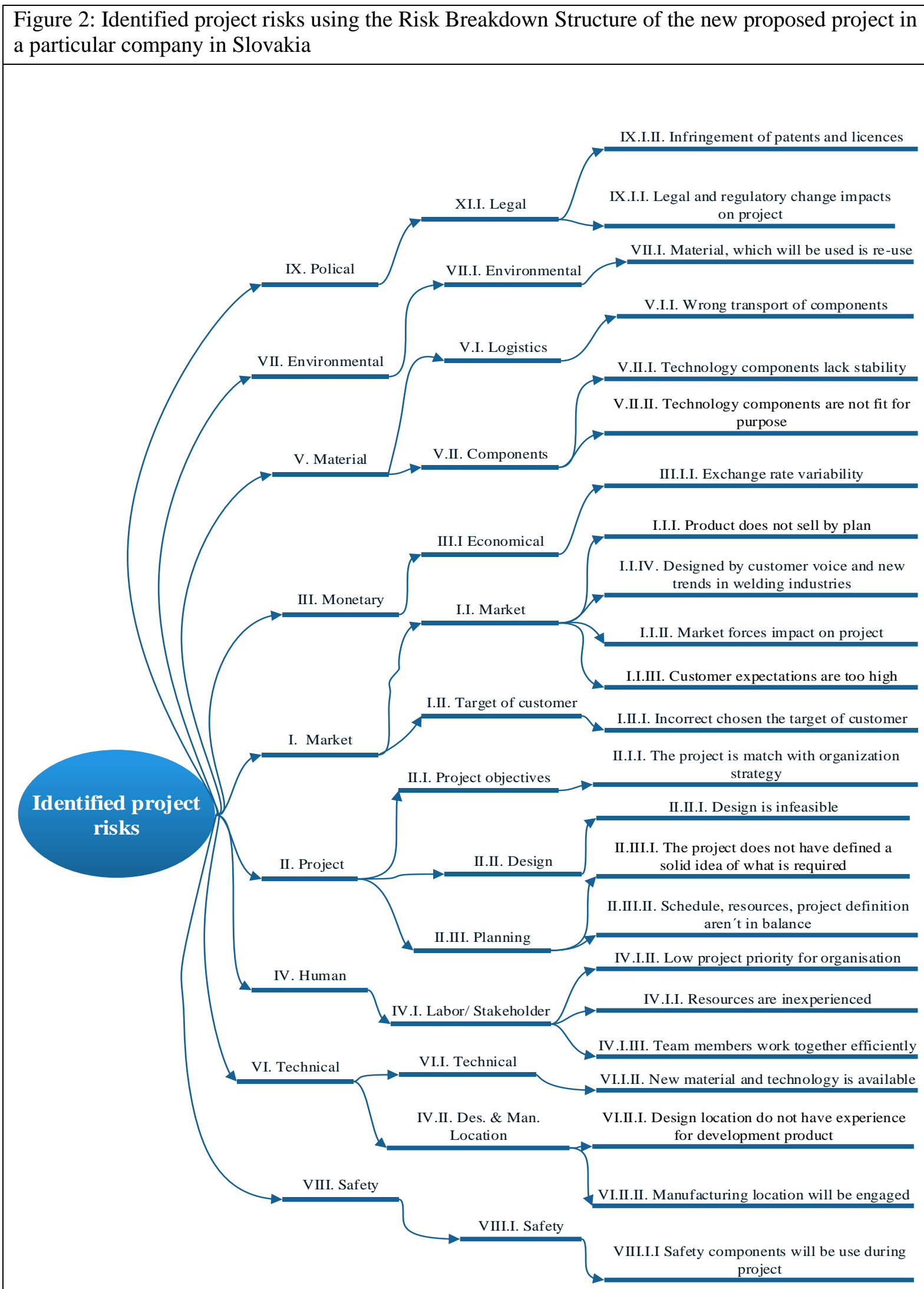

\section{Source: Authors}

22 risks were identified in this process. The risks were both positive and negative. We sorted the 5 main negative risks, which would most affect the project. 
1. Risk name: The project does not have a defined solid idea of what it is

Risk Category: Project - Planning

Description: A solid idea and requirements are one of more important parts of the project. If the team doesn't have a solid idea and a clear concept of the project, the team can make mistakes during the design phase. The location, where the product will be designed and manufactured has very low skills so we can assume, that cumulative risks can appear. Those risks affect the schedule, resources, and expenses of the project.

Current mitigation: For elimination of this risk, primary market research was created. The market research was created with customer expectations, design expectation, competitors products, market share and others market forces in mind.

2. Risk name: Product does not sell according to plan

Risk Category: Market - Market

Description: It is possible to say, that this risk is one of the biggest. This risk arises due to bad design, if the product doesn't respect customer expectations or if the product consists of features, which customers don't need. In addition, this risk can arise if a new competitor appears, who can bring a newer product with a lower price. This risk can affect project the most, because if the pieces which are planned do not sell, they will be lost.

Current mitigation: When the team started this project they must create a competitor comparison of potential substitute products and competitors. The project manager must still monitor all market forces, which can affect the project.

3. Risk name: Technology components are not fit for purpose of this project

Risk Category: Material- Components

Description: A designer wants to create a product which will be at the right cost for the budget so they often use cheaper components or similar components. Those components work right during tests, but they sometimes may break. When this component breaks it may affect the duration of the project, because of they can spoil the product. The worst case is if it affects customer satisfaction, customer reviews and the goodwill of the enterprise.

Current mitigation: The enterprise has datasheets of components which are used as substitute components for each product. Those similar components are of high quality.

4. Risk name: Customer expectations are too high

Risk Category: Market - Market

Description: Customer expectations are also one of the main risks. It is necessary to know and define customer expectations. Expectations are sometimes too high, and hence it is impossible to fulfill them. Expectations may then affect sales of the product.

Corrective mitigations: A survey is prepared for each project which is designed and manufactured by the enterprise. Survey and market research was conducted for this project. The market research defined the target customer, who is important for our project and their expectation of the product.

5. Risk name: Design location does not have the experience for the development of the product

Risk Category: Technical - Design \& Manuf. location

Description: The design and manufacture location has low skills and experience with designing or manufacturing this product. It is a new product, which is used for the diversification of the portfolio of the enterprise. This risk may avoid increasing secondary risks such as inccorect design components, the product doesn't respect customer requirements, the product is impossible to manufacture in the enterprise, less labor staff skills, etc.

Current mitigation: The design is made with manufacturing capabilities and technical capacities taken into account. Manufacture location has software, skills and experience for this product, which they can use in the manufacture process.

\section{Conclusion}

In general, it is possible to say, that every project activity is influenced by risks. Nowadays projects are more comprehensive and with high costs. It is needed to choose the best risk management process, which 
will reflect the company, project, and environmental changes and conditions. The project risk identification process brings to enterprises lot of benefits. The benefit of risk identification is using the risk management process. It is possible to consider that risk identification is the main gate to identify opportunities and threats. It can provide a new and comprehensive view of a project and the decision about project characteristics. Risk identification is considered by project managers as a unnecessary part of project management. Team members are responsible to manage project risks and top managers are responsible for the corporate culture of each enterprise. The results of this paper are benefits not only for the enterprise BPS, but also for every enterprise which also deals with risks.

\section{Acknowledgement}

Publication of this paper was supported by the Scientific Grant Agency of the Ministry of Education, Science, Research and Sport of the Slovak Republic - VEGA No. 1/0560/16. Risk Management of Small and Medium Sized Enterprises in Slovakia as Prevention of Company Crises. This work was supported by the Internal Grant Scheme of Faculty of Security Engineering, University of Zilina from the grant No. 201801.

\section{References}

Burger R. (2017). The 5 Biggest Project Management Trends Shaping 2018. Retrieved from: https://blog.capterra.com/the-5biggest-project-management-trends-shaping-2018

Faith N. (2011). Enterprise risk management strategy. Human Sciences Reseach Council 2011. 31 pages

Flaherty J. (2006). Enterprise Risk Management - Integrated Framework -Executive summary COSO 16 pages

Muzaimi. H, et al. (2017). Integrated management system: The integration of ISO 9001 ISO 14001, OHSAS 180001 and ISO 31000. AIP Conference Proceedings 1818, 2034

Investopedia. 2014. Market dynamics. Retrieved from: https://www.investopedia.com/terms/m/market-dynamics.asp

ISO 31000 management - Principles and guidelines

KPMG. (2017). Project Management Survey 2017. Retrieved from:

https://assets.kpmg.com/content/dam/kpmg/nz/pdf/July/projectmanagementsurvey-kpmg-nz.pdf

Masár M, Hudáková M. (2017). Benefits of use integration ISO 21500:2012 and ISO 31000:2009 in project risk management. Karviná Ph.D. conference on business and economics proceedings of the 10th international scientific conference: November 1-3. 2017 Karviná, Czech Republic. Karviná: Silesian University, 2017. - ISBN 978-80-7510-265-2. Online, s. 124-133.

Olechowski A et al. (2017). The professionalization of risk management: What role can the ISO 31000 risk management principles play International Journal of Project management 34,8. 1568-1578 pages

OSPMI (Office of Statewide Project Management Improvement). (2007). Project Risk Management Handbook - Threats and Opportunities Retrieved from http://www.dot.ca.gov/documents/project_risk_management_handbook_20070502.pdf

PMI. (2017). Pulse of the profession 2017. Retrieved from: https://www.pmi.org/-

/media/pmi/documents/public/pdf/learning/thought-leadership/pulse/pulse-of-the-profession-2017.pdf

PMI. (2009). Practise Standards for Project Risk Management. Pennsylvania 2009, 128 pages. ISBN: 978-1-933890-38-8.

Project Management Institute. (2004). A guide to the project management body of knowledge (PMBOK guide). Newtown Square, Pa: Project Management Institute.

PROOFHUB. (2017). Agile Project Management Trends for 2017. Retrieved from: https://www.workzone.com/blog/top-10project-management-trends-for-2017

Stark J. (2011). Product Lifecycle management. Springer 2011. 584 pages. ISBN: 978-0-85729-545-3.

Tinnirello P. (2013). New Directions in Project Management Auerbach Publications 560 pages. ISBN: 0-84-931190-X 